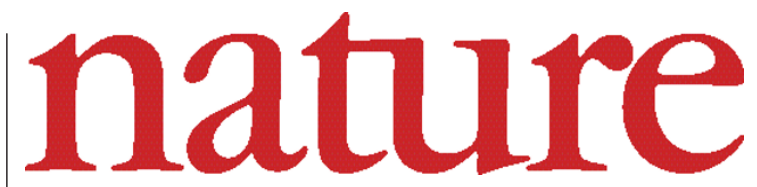

16 January 2003 Volume 421 Issue no 6920

\title{
Climate come-uppance delayed
}

A proposal to control greenhouse gases may have been dead on arrival in the US Senate - but its time will surely come.

A modest target for the stabilization and subsequent reduction of greenhouse-gas emissions. Legal authority for the Environmental Protection Agency to regulate such emissions. Establishment of some of the rules needed to foster a free and open market for emissions trading. Some fine-tuning of the federal government's climate-change research programme.

The central points of the American Investments for Reduction of Emissions Act of 2003, which was introduced last week by senators John McCain (Republican, Arizona) and Joe Lieberman (Democrat, Connecticut), would be regarded by many as a perfectly reasonable set of precautions against the likely dangers of global climate change.

Will the US Senate enact the measure? Not a chance. After due consideration at a hearing of the commerce committee on 8 January, the measure is going nowhere fast in the Senate. The Bush administration is dismissive of it and the House of Representatives is uninterested.

Two of Bush's most formidable opponents - McCain inside the Republican party, Lieberman outside it - know this well enough. Their real intention is not to pass a bill. It is to send a signal that the president's nonchalant disregard of this issue will one day come back to haunt him (see page 202).

McCain picked up his own interest in the issue on the campaign trail for the last presidential election. In the cold school halls of Iowa and New Hampshire, the environmentally hawkish senator gained the impression that young people in America feel betrayed by
Washington's failure to engage with the problem of global warming. He changed tack on the issue, and now joins long-time environmentalist Lieberman in addressing it.

But the two men are also sending out a message to the world at large: that Bush doesn't speak for America on climate change. Their concerns are quietly shared by many Americans - in fact by most, according to polls. And around America, two-thirds of states are taking measures that will encourage a reduction in greenhouse-gas emissions.

Meanwhile, elsewhere in the world, ratification of the Kyoto Protocol is proceeding far more vigorously than its supporters anticipatedpartly on account of the characteristic petulance with which Bush saw fit to withdraw from it. Instead of using his exit as an excuse to renege on the agreement, as they might well have done, close allies with conservative governments have confirmed their plans to ratify. Last month, indeed, Canada became the hundredth nation to do so. Russia is likely to come on board too, ensuring that participation reaches the threshold to bring the treaty into force without US participation.

In the long run, people who have a sense of the appropriate role of the United States in the world - people such as McCain and Lieberman - will regain influence. Something akin to the bill that the dynamic duo introduced last week will one day pass into law. While waiting for that day, the rest of the world must confront the challenge of global warming on its own.

\section{More heat, less light on Lomborg}

\section{A Danish committee has picked an appropriate target and misfired.}

$\mathrm{N}$ ot surprisingly, last week's ruling by the Danish Committees on Scientific Dishonesty (DCSD) that Bjørn Lomborg, in his controversial book The Skeptical Environmentalist, selected data in a "severely biased" manner and exhibited poor scientific practice (see page 201) received widespread international media coverage. But whether the DCSD emerged with credit also deserves reflection.

Lomborg's hypothesis that warnings issued by environmentalists and scientists are unwarranted, presented in the book rather than in the peer-reviewed literature, has been widely criticized by researchers. But what is the DCSD's authority to tackle what many consider a polemical rather than scientific book?

The DCSD was the first European body to be set up — by the Danish Research Agency - to examine issues of scientific misconduct, and it is still unusual in being mandated to consider any complaint about any scientist, or any scientific work, emerging from both the private and public sectors. A look at its guiding principles (see http://www.forsk.dk/eng/index.htm) and its judgement (see www.forsk.dk/uvvu/nyt/udtaldebat/bl_decision.htm) confirms that the DCSD has the freedom to assess the case because, arguably, Lomborg presented himself as an academic and his book as a scientific argument. Appropriately enough, the DCSD emphasizes that it is assessing Lomborg's scientific standards, not his conclusions.

The national context of this independent assessment is relevant here. Lomborg was made director of the politically influential Danish
Environmental Assessment Institute, founded by the new right-wing government after the 2001 elections, solely on the strength of it. According to its own statutes, the institute must be headed by a scientist of appropriate research experience, whereas Lomborg has little additional experience.

Lomborg's claims in his book are certainly significant and potentially influential. The Danish public, at least, has the right to know whether he is arguing on scientifically rigorous grounds, not least given the influence of his position.

Unfortunately, the DCSD has left itself in a weak position. It did not conduct an independent analysis of the book but relied on published criticisms, especially a controversial selection published by Scientific American. Even to call this judgement's basis a 'meta-analysis' would be too generous: there is, for example, no justification given for the particular selection of published critiques. Furthermore, through a tangled combination of translation and legalese, the committee's judgement characterizes Lomborg as "objectively dishonest" while at the same time stating that they have no evidence for what most people would call dishonesty: deliberate misrepresentation. That subtle, not to say tortuous, distinction has been lost in the media coverage.

There remains a need for rigorous scrutiny of Lomborg's methods, given his prominence, his claims to serious analysis, and the polarized debate surrounding his book. But this episode leaves everyone little wiser, and the waters surrounding Lomborg even muddier. 